\title{
A Modular Synthesis of the Lamellarins: Total Synthesis of Lamellarin G Trimethyl Ether
}

Scott T. Handy, Yanan Zhang, and Howard Bregman

Department of Chemistry, State University of New York at Binghamton, Binghamton,

NY 13902

$\underline{\text { Table of Contents }}$

Preparation of 3,4-dimethoxyphenylethyl alcohol $5 \quad$ S3

Preparation of 2-[2-(2-bromo-4,5-dimethoxyphenyl)ethoxy]tetrahydropyran 6 S3

Preparation of 2-(2-hydroxyethyl)-4,5-dimethoxyphenylboronic acid $2 \quad$ S4

Preparation of 2-(3,4-dimethoxyphenoxy)tetrahydropyran 8 S4

Preparation of 2-(2-Bromo-4,5-dimethoxyphenoxy)tetrahydropyran $9 \quad$ S4

Preparation of 2-hydroxy-4,5-dimethoxyphenylboronic acid $\mathbf{3}$ S5

${ }^{1} \mathrm{H}$ spectrum of 4-Bromopyrrole-1,2-dicarboxylic acid 1-tert-butyl ester

2-ethyl ester 11.

${ }^{13} \mathrm{C}$ spectrum of 4-Bromopyrrole-1,2-dicarboxylic acid 1-tert-butyl ester

2-ethyl ester 11

${ }^{1} \mathrm{H}$ spectrum of 4-(3,4-dimethoxyphenyl)-1 $H$-pyrrole-2-carboxylic acid ethyl ester 12

${ }^{13} \mathrm{C}$ spectrum of 4-(3,4-dimethoxyphenyl)-1H-pyrrole-2-carboxylic acid $\begin{array}{ll}\text { ethyl ester } 12 & \text { S9 }\end{array}$

${ }^{1} \mathrm{H}$ spectrum of 5-bromo-4-(3,4-dimethoxyphenyl)-1 $\mathrm{H}$-pyrrole-2-carboxylic acid ethyl ester $\mathbf{1 3}$

${ }^{13} \mathrm{C}$ spectrum of 5-bromo-4-(3,4-dimethoxyphenyl)-1 $H$-pyrrole-2-carboxylic acid ethyl ester $\mathbf{1 3}$

${ }^{1} \mathrm{H}$ spectrum of 4-(3,4-dimethoxyphenyl)-5-[2-(2-hydroxyethyl)-4,5 dimethoxyphenyl]-1 $H$-pyrrole-2-carboxylic acid ethyl ester 14

${ }^{13} \mathrm{C}$ spectrum of 4-(3,4-dimethoxyphenyl)-5-[2-(2-hydroxyethyl)-4,5 dimethoxyphenyl]-1 $H$-pyrrole-2-carboxylic acid ethyl ester 14 
${ }^{1} \mathrm{H}$ spectrum of 1-(3,4-dimethoxyphenyl)-8,9-dimethoxy-5,6-dihydropyrrolo

[2,1-a]isoquinoline-3-carboxylic acid ethyl ester 15

${ }^{13} \mathrm{C}$ spectrum of 1-(3,4-dimethoxyphenyl)-8,9-dimethoxy-5,6-dihydropyrrolo

[2,1- $a]$ isoquinoline-3-carboxylic acid ethyl ester $\mathbf{1 5}$

${ }^{1} \mathrm{H}$ spectrum of 2-Bromo-1-(3,4-dimethoxyphenyl)-8,9-dimethoxy-5,6-

dihydropyrrolo[2,1-a]isoquinoline-3-carboxylic acid ethyl ester 16

${ }^{13} \mathrm{C}$ spectrum of 2-Bromo-1-(3,4-dimethoxyphenyl)-8,9-dimethoxy-5,6-

dihydropyrrolo[2,1-a]isoquinoline-3-carboxylic acid ethyl ester 16

${ }^{1} \mathrm{H}$ spectrum of 14-(3,4-dimethoxyphenyl)-2,3,11,12-tetramethoxy-8,9-dihydro-6 $\mathrm{H}$ chromeno[4',3':4,5]pyrrolo[2,1-a]isoquinolin-6-one

(Lamellarin $\mathrm{G}$ trimethyl ether).

${ }^{13} \mathrm{C}$ spectrum of 14-(3,4-dimethoxyphenyl)-2,3,11,12-tetramethoxy-8,9-dihydro- $6 \mathrm{H}$ chromeno[4',3':4,5]pyrrolo[2,1-a]isoquinolin-6-one

(Lamellarin G trimethyl ether). 


\section{Supporting Information.}

3,4-dimethoxyphenylethyl alcohol (5). A solution of $5.88 \mathrm{~g}$ (30 mmol) of 3,4dimethoxyphenyl acetic acid, $2.79 \mathrm{~g}$ (72 mmol) of $\mathrm{NaBH}_{4}$ in $78 \mathrm{~mL}$ freshly distilled THF was chilled to $0^{\circ} \mathrm{C}$. To this solution was added dropwise $7.59 \mathrm{~g}(30 \mathrm{mmol})$ of $\mathrm{I}_{2}$ in $18 \mathrm{~mL}$ freshly distilled THF. The reaction was heated to reflux for 18 hours. The reaction was cooled to ambient temperature. To the reaction was added dropwise $\mathrm{MeOH}$ until the solution became clear. The reaction was stirred $30 \mathrm{~min}$ and the solvent was removed in vacuo. The resulting residue was dissolved in $20 \%$ aqueous $\mathrm{NaOH}(13.0 \mathrm{~g}$ in $60 \mathrm{~mL}$ of water). The solution was stirred for 4 hours then extracted with $\mathrm{CH}_{2} \mathrm{Cl}_{2}(3 \times 50 \mathrm{~mL})$. The combined organic layers were washed with water, and dried with anhydrous magnesium sulfate. The solvent was removed in vacuo to afford $4.95 \mathrm{~g}(91.2 \%)$ of $\mathbf{5}$ as a colorless oil. ${ }^{1} \mathrm{H}$ NMR (360 MHz, $\left.\mathrm{CDCl}_{3}\right) \delta 6.72-6.78(\mathrm{~m}, 3 \mathrm{H}), 3.85(\mathrm{~s}, 3 \mathrm{H}), 3.83(\mathrm{~s}, 3 \mathrm{H}), 3.79$ (t, $2 \mathrm{H}, \mathrm{J}=7.2), 2.78(\mathrm{t}, 2 \mathrm{H}, \mathrm{J}=7.2)$

2-[2-(2-bromo-4,5-dimethoxyphenyl)ethoxy]-tetrahydropyran (6). A solution of 4.95 $\mathrm{g}(27.3 \mathrm{mmol})$ of $\mathbf{5}$ in $100 \mathrm{~mL}$ of $\mathrm{DMF}$ was chilled to $0^{\circ} \mathrm{C}$. To this solution was added portionwise $4.87 \mathrm{~g}(27.4 \mathrm{mmol})$ of $\mathrm{N}$-bromosuccinimide. The reaction was warmed to room temperature overnight. The reaction was then quenched with $80 \mathrm{~mL}$ of water and extracted with EtOAc (3 x $60 \mathrm{~mL})$. The combined organic layers were washed with aqueous $\mathrm{Na}_{2} \mathrm{~S}_{2} \mathrm{O}_{3}$, water and brine, dried with magnesium sulfate and then concentrated in vacuo to afford $7.1 \mathrm{~g}(99.6 \%)$ of 2-bromo-4,5-dimethoxyphenylethyl alcohol as a yellow oil. ${ }^{1} \mathrm{H}$ NMR $\left(360 \mathrm{MHz}, \mathrm{CDCl}_{3}\right) \delta 6.92(\mathrm{~s}, 1 \mathrm{H}), 6.72(\mathrm{~s}, 1 \mathrm{H}), 3.76(\mathrm{~m}, 8 \mathrm{H}), 2.86$ $(\mathrm{t}, 2 \mathrm{H}, \mathrm{J}=5.5) . \quad$ A solution of $7.13 \mathrm{~g}(27.3 \mathrm{mmol})$ of the above alcohol, $3.75 \mathrm{~mL}(41.0$ mmol) of 1,2-dihydropyran (DHP) and $690 \mathrm{mg}(3.7 \mathrm{mmol})$ of pyridinium $p$ - 
toluenesulfonic acid in $33 \mathrm{~mL}$ of dichloromethane was stirred overnight at ambient temperature. The reaction was diluted with $100 \mathrm{~mL}$ of dichloromethane, washed with saturated aqueous $\mathrm{NaHCO}_{3}$ and water, and dried with magnesium sulfate. The solvent was removed in vacuo to afford $9.4 \mathrm{~g}(96.6 \%)$ of $\mathbf{6}$ as a yellow solid. ${ }^{1} \mathrm{H} \mathrm{NMR}(360 \mathrm{MHz}$, $\left.\mathrm{CDCl}_{3}\right) \delta 6.94(\mathrm{~s}, 1 \mathrm{H}), 6.78(\mathrm{~s}, 1 \mathrm{H}), 4.55(\mathrm{~m}, 1 \mathrm{H}), 3.87(\mathrm{~m}, 1 \mathrm{H}), 3.80(\mathrm{~m}, 6 \mathrm{H}), 3.72(\mathrm{~m}$, 1H), $3.55(\mathrm{~m}, 1 \mathrm{H}), 3.42(\mathrm{~m}, 1 \mathrm{H}), 2.93(\mathrm{t}, 2 \mathrm{H}, \mathrm{J}=7.2), 1.40-1.80(\mathrm{~m}, 6 \mathrm{H})$.

2-(2-hydroxyethyl)-4,5-dimethoxyphenylboronic acid (2). A solution of $9.4 \mathrm{~g}(27.2$ mmol) of 6 in $100 \mathrm{~mL}$ of freshly distilled THF was chilled to $-78^{\circ} \mathrm{C}$ before $25.6 \mathrm{~mL}$ (41.0 mmol) of 1.6 M n-BuLi in hexane was slowly added. The reaction was stirred $15 \mathrm{~min}$ and $9.5 \mathrm{~mL}(41.0 \mathrm{mmol})$ of triisopropylborate was added. The reaction was stirred at this temperature for 2 hours then warmed up to ambient temperature overnight. To the reaction mixture was added $40 \mathrm{~mL}$ of $1 \mathrm{~N} \mathrm{HCl}$ and this solution was stirred for 1 hour. The layers were separated and the aqueous layer was extracted with THF (2 x $40 \mathrm{~mL})$. The combined organic layers were washed with water and dried with anhydrous $\mathrm{Na}_{2} \mathrm{SO}_{4}$. The solvent was removed in vacuo to give $\mathbf{2}$. The crude product was recrystallized in 10 $\mathrm{mL}$ of water to afford $3.84 \mathrm{~g}(62.5 \%)$ of $\mathbf{2}$ as a white solid. ${ }^{1} \mathrm{H} \mathrm{NMR}\left(360 \mathrm{MHz}, \mathrm{CDCl}_{3}\right) \delta$ $7.23(\mathrm{~s}, 1 \mathrm{H}), 6.68(\mathrm{~s}, 1 \mathrm{H}), 4.20(\mathrm{t}, 2 \mathrm{H}, \mathrm{J}=7.2), 3.90(\mathrm{~s}, 3 \mathrm{H}), 3.88(\mathrm{~s}, 3 \mathrm{H}), 2.89(\mathrm{t}, 2 \mathrm{H}, \mathrm{J}=$ $7.2)$.

2-(3,4-dimethoxyphenoxy)tetrahydropyran (8). A solution of $1.0 \mathrm{~g}(6.5 \mathrm{mmol})$ of 3,4dimethoxyphenol, $1.78 \mathrm{~mL}$ (19.5 mmol) of 1,2-dihydropyran (DHP) and $163.0 \mathrm{mg}(0.65$ mmol) of pyridinium $p$-toluenesulfonic acid in $5 \mathrm{~mL}$ of dichloromethane was stirred 4 hours. To the reaction was added $30 \mathrm{~mL}$ of dichloromethane and washed with saturated aqueous sodium bicarbonate, water and brine, and then dried over anhydrous sodium 
sulfate. The solvent was removed in vacuo to afford $1.55 \mathrm{~g}(100 \%)$ of $\mathbf{8}$ as a white solid. ${ }^{1} \mathrm{H}$ NMR $\left(360 \mathrm{MHz}, \mathrm{CDCl}_{3}\right) \delta 6.73(\mathrm{~d}, 1 \mathrm{H}, \mathrm{J}=7.2), 6.55-6.62(\mathrm{~m}, 2 \mathrm{H}), 5.28(\mathrm{t}, 1 \mathrm{H}, \mathrm{J}=$ 3.3), $3.92(\mathrm{~m}, 1 \mathrm{H}), 3.83(\mathrm{~s}, 3 \mathrm{H}), 3.81(\mathrm{~s}, 3 \mathrm{H}), 3.58(\mathrm{~m}, 1 \mathrm{H}), 1.56-2.00(\mathrm{~m}, 6 \mathrm{H})$

2-(2-Bromo-4,5-dimethoxyphenoxy)tetrahydropyran (9). A solution of $1.25 \mathrm{~g}(5.27$ $\mathrm{mmol}$ ) of $\mathbf{8}$ and $4.0 \mathrm{~g}$ of sodium carbonate in $30 \mathrm{~mL}$ of DMF was chilled to $0^{\circ} \mathrm{C}$. To this solution was added in portions $1.31 \mathrm{~g}(7.38 \mathrm{mmol})$ of NBS. The reaction was stirred overnight before $50 \mathrm{~mL}$ of water was added and extracted with ethyl acetate $(3 \times 50 \mathrm{~mL})$. The combined organic layers were dried over potassium carbonate and concentrated in vacuo to afford $1.36 \mathrm{~g}(81.7 \%)$ of 9 as a yellow oil. ${ }^{1} \mathrm{H}$ NMR $\left(360 \mathrm{MHz}, \mathrm{CDCl}_{3}\right) \delta 6.99$ $(\mathrm{s}, 1 \mathrm{H}), 6.79(\mathrm{~s}, 1 \mathrm{H}), 5.34(\mathrm{t}, 1 \mathrm{H}, \mathrm{J}=2.9), 3.95(\mathrm{~m}, 1 \mathrm{H}), 3.84(\mathrm{~s}, 3 \mathrm{H}), 3.83(\mathrm{~s}, 3 \mathrm{H}), 3.62$ $(\mathrm{m}, 1 \mathrm{H}), 1.20-1.94(\mathrm{~m}, 6 \mathrm{H})$

2-hydroxy-4,5-dimethoxyphenylboronic acid (3). A solution of $670 \mathrm{mg}(2.12 \mathrm{mmol}) 9$ in $20 \mathrm{~mL}$ of freshly distilled THF was chilled to $-78^{\circ} \mathrm{C}$. To this solution was added slowly $2.0 \mathrm{~mL}(3.2 \mathrm{mmol})$ of $1.6 \mathrm{M} \mathrm{n}-\mathrm{BuLi}$ in hexane. The reaction was stirred $15 \mathrm{~min}$. To the mixture was added $0.73 \mathrm{~mL}(3.2 \mathrm{mmol})$ of triisopropylborate. The reaction was stirred at this temperature for 2 hours before warming to ambient temperature overnight. To the reaction mixture was added $15 \mathrm{~mL}$ of $1 \mathrm{~N} \mathrm{HCl}$ and this solution was stirred for 1 hour. The layers were separated and the aqueous layer was extracted with $30 \mathrm{~mL}$ of THF. The combined organic layers were washed with water and dried with anhydrous $\mathrm{Na}_{2} \mathrm{SO}_{4}$. The solvent was removed to afford $1.33 \mathrm{~g}$ (crude product) of $\mathbf{3}$ as a green solid. ${ }^{1} \mathrm{H}$ NMR $\left(360 \mathrm{MHz}, \mathrm{CDCl}_{3}\right) \delta 7.06(\mathrm{~s}, 1 \mathrm{H}), 6.60(\mathrm{~s}, 1 \mathrm{H}), 3.87(\mathrm{~s}, 3 \mathrm{H}), 3.80(\mathrm{~s}, 3 \mathrm{H})$. 
4-Bromopyrrole-1,2-dicarboxylic acid 1-tert-butyl ester 2-ethyl ester (11).

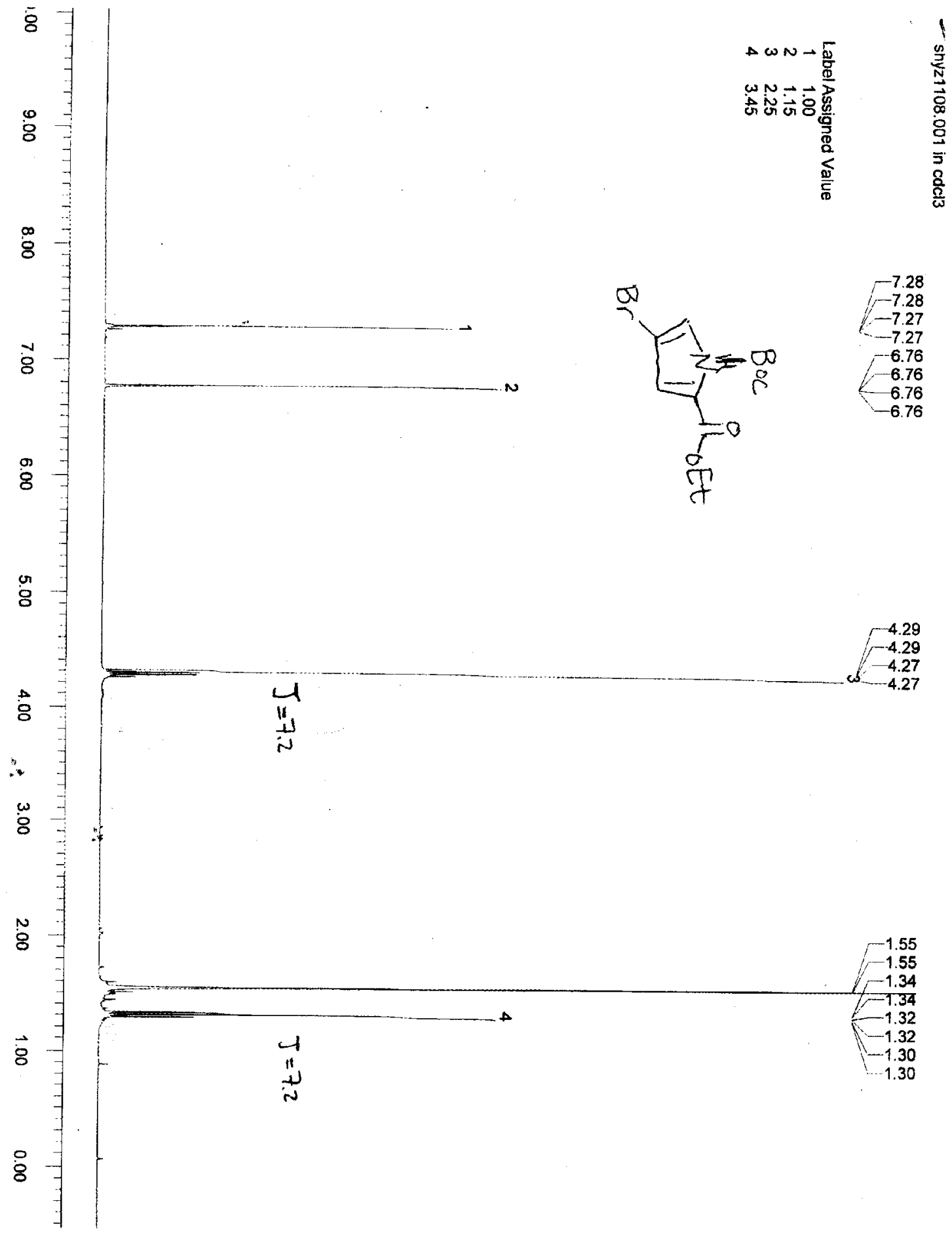




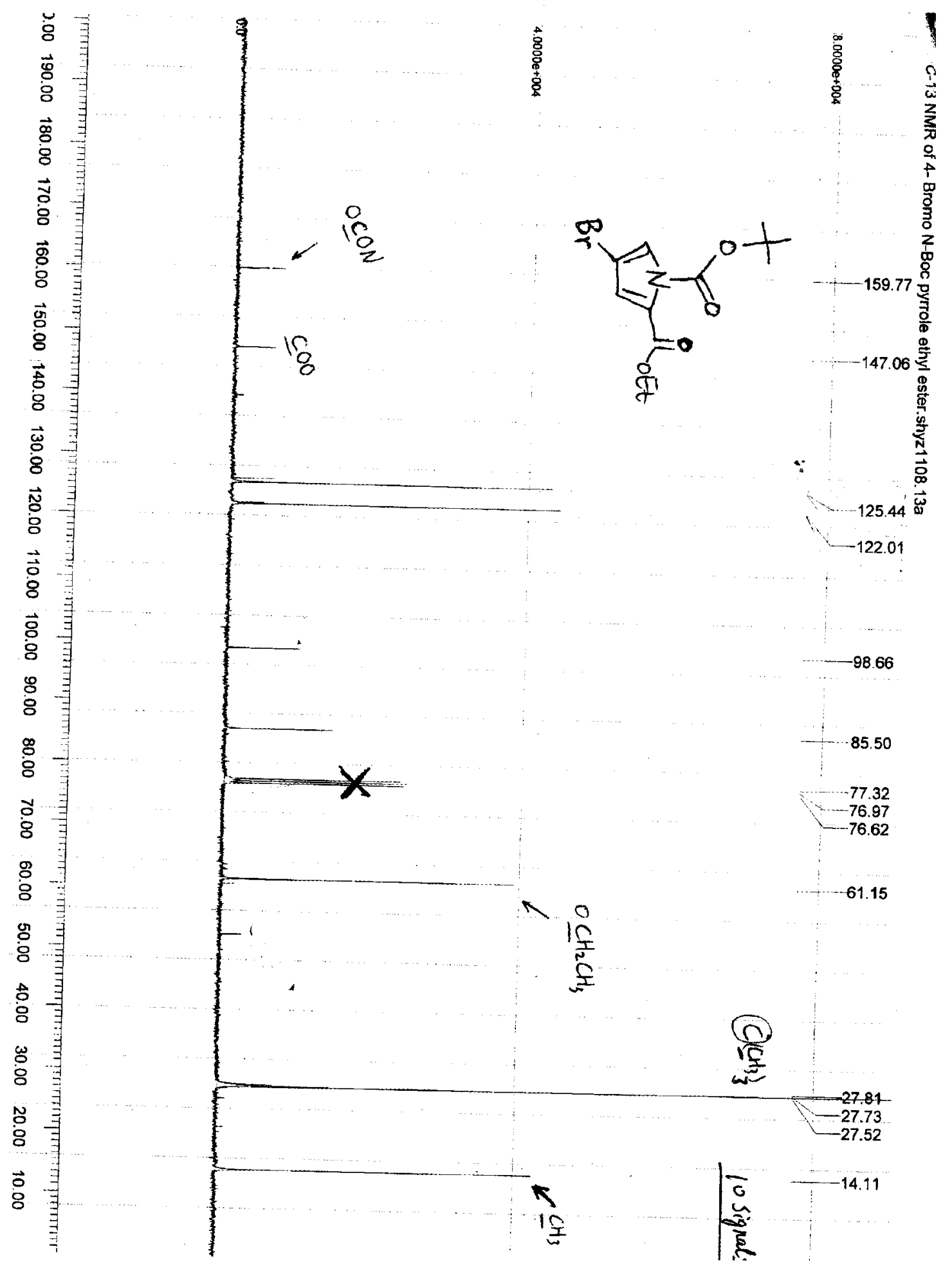




\section{4-(3,4-dimethoxyphenyl)-1H-pyrrole-2-carboxylic acid ethyl ester (12).}

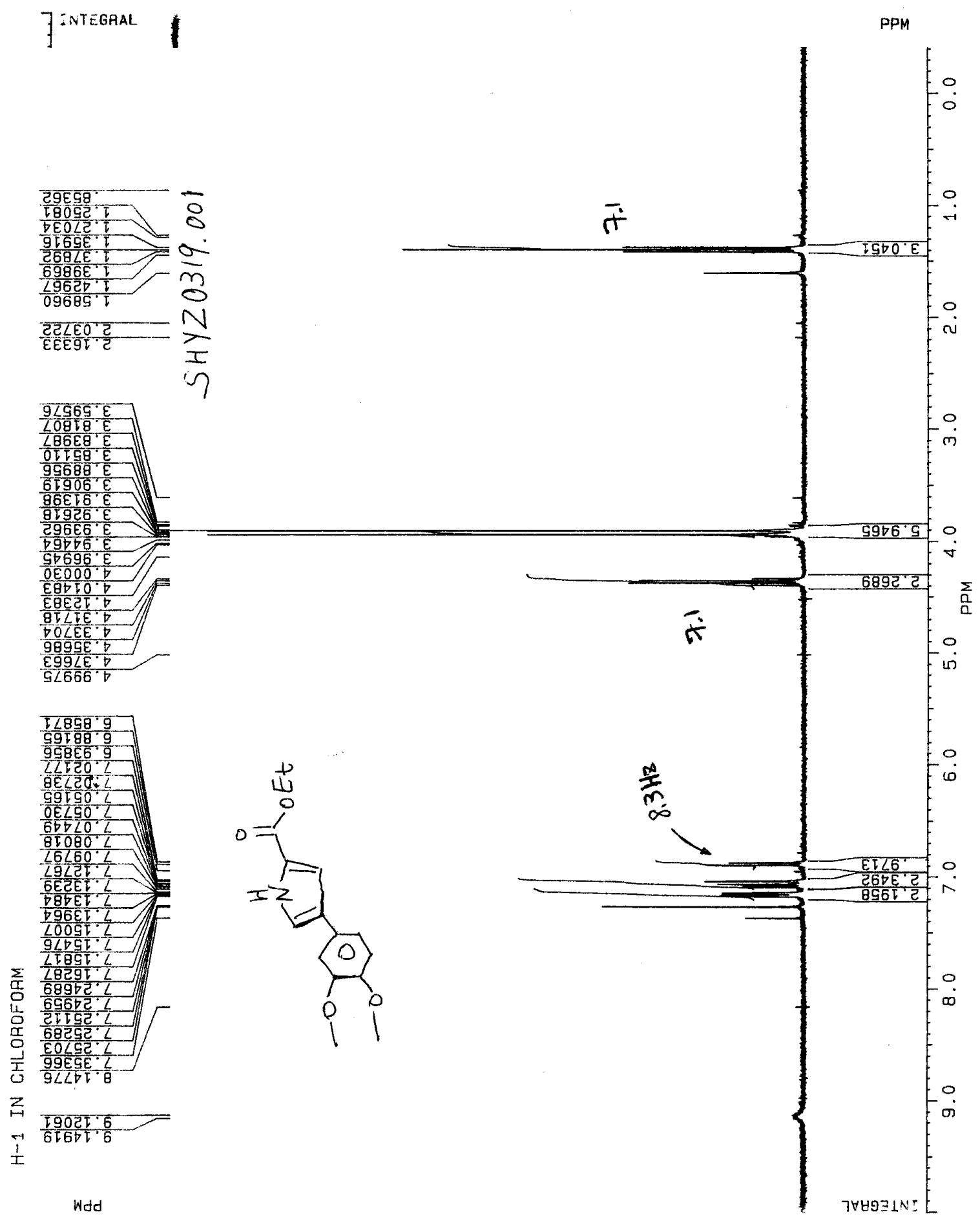




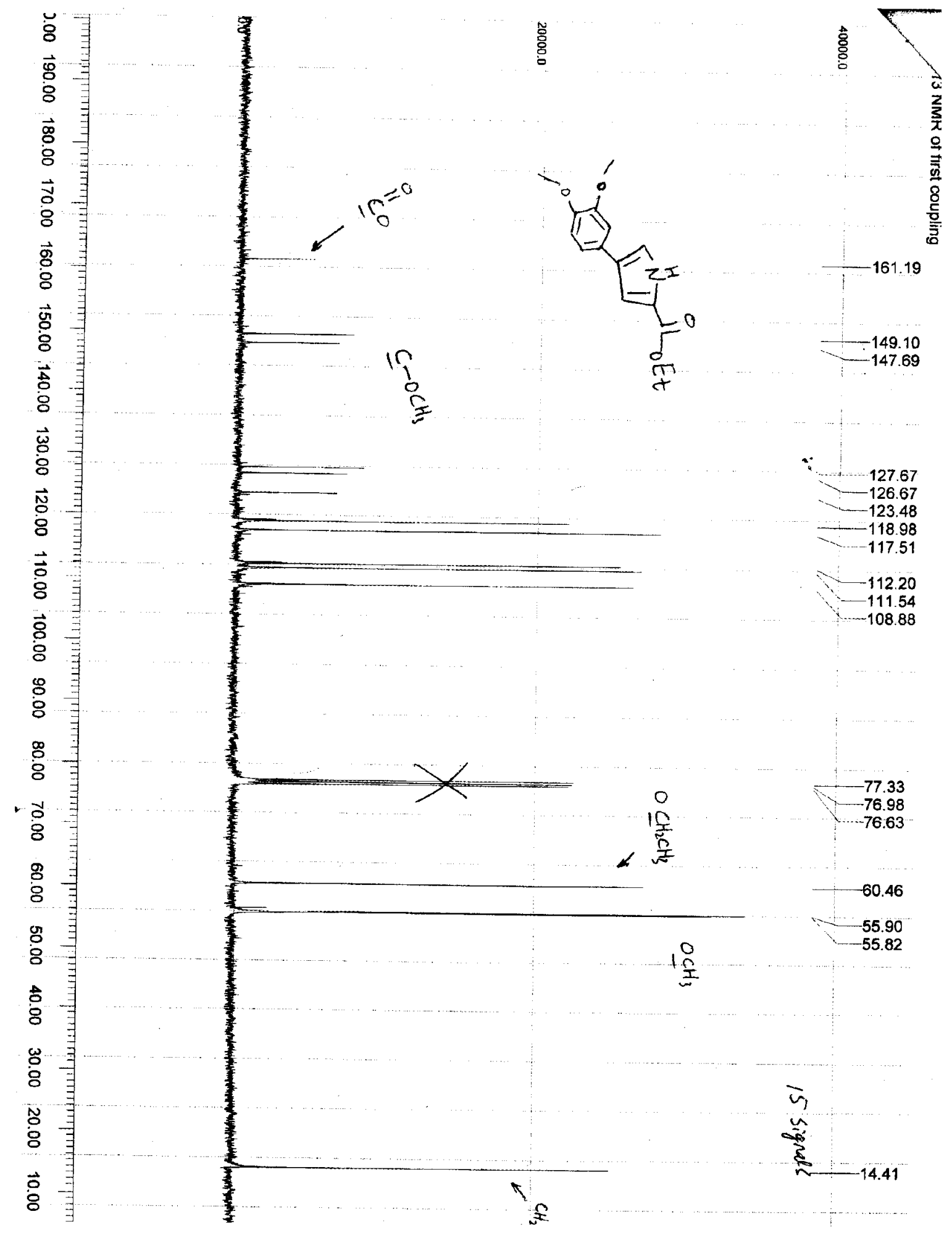


5-bromo-4-(3,4-dimethoxyphenyl)-1H-pyrrole-2-carboxylic acid ethyl ester (13).

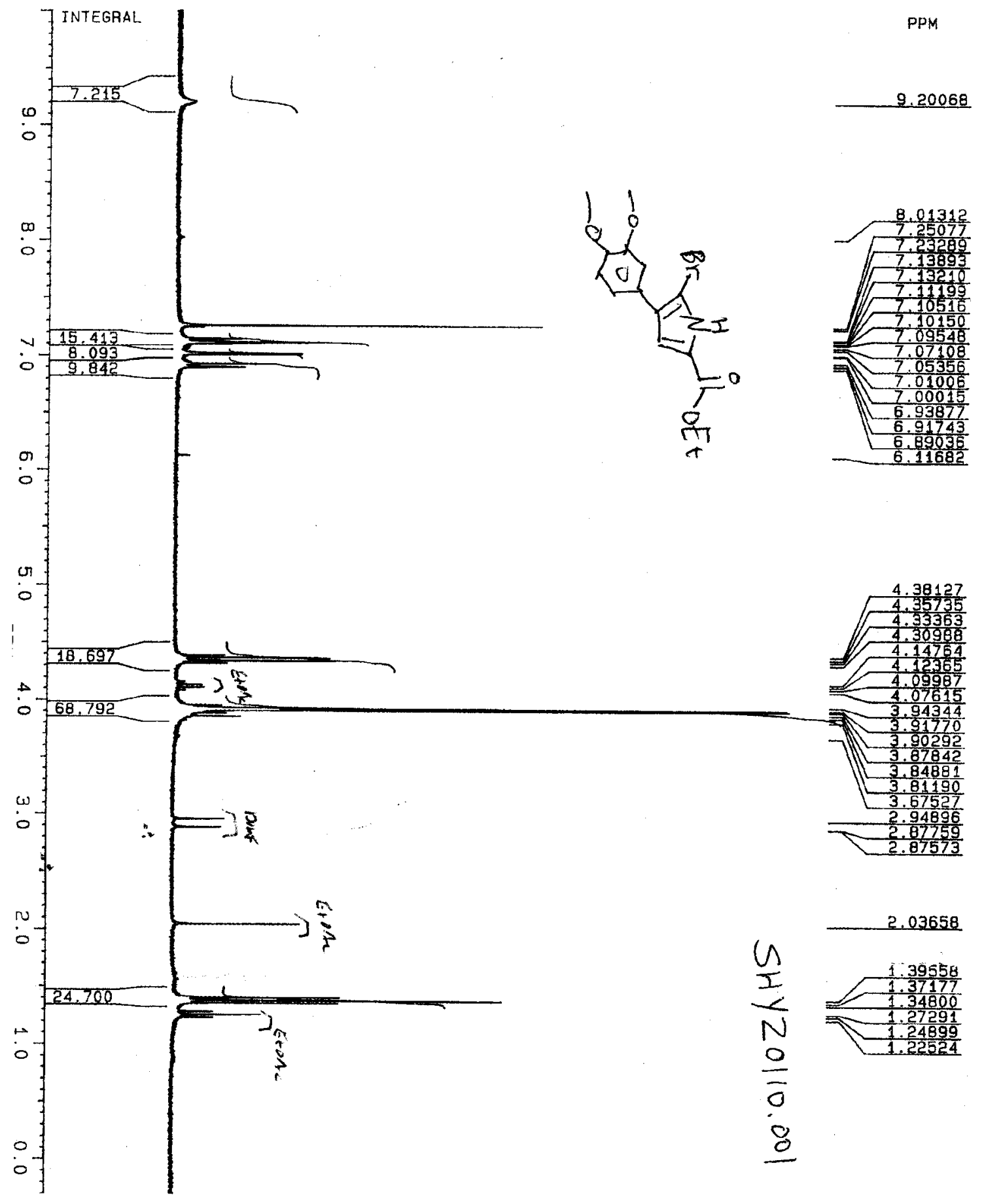




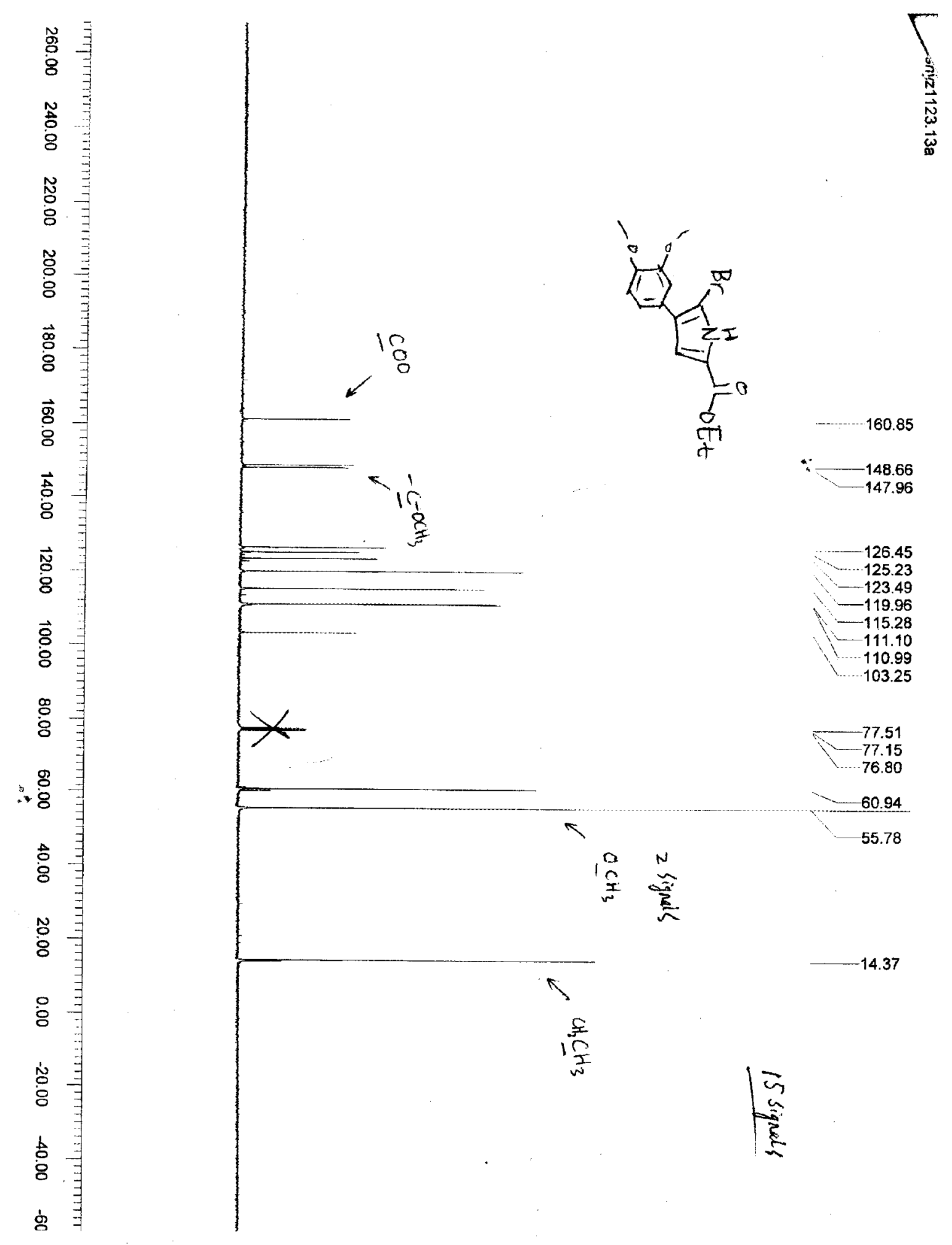


4-(3,4-dimethoxyphenyl)-5-[2-(2-hydroxyethyl)-4,5-dimethoxyphenyl]-1H-pyrrole-2carboxylic acid ethyl ester (14).

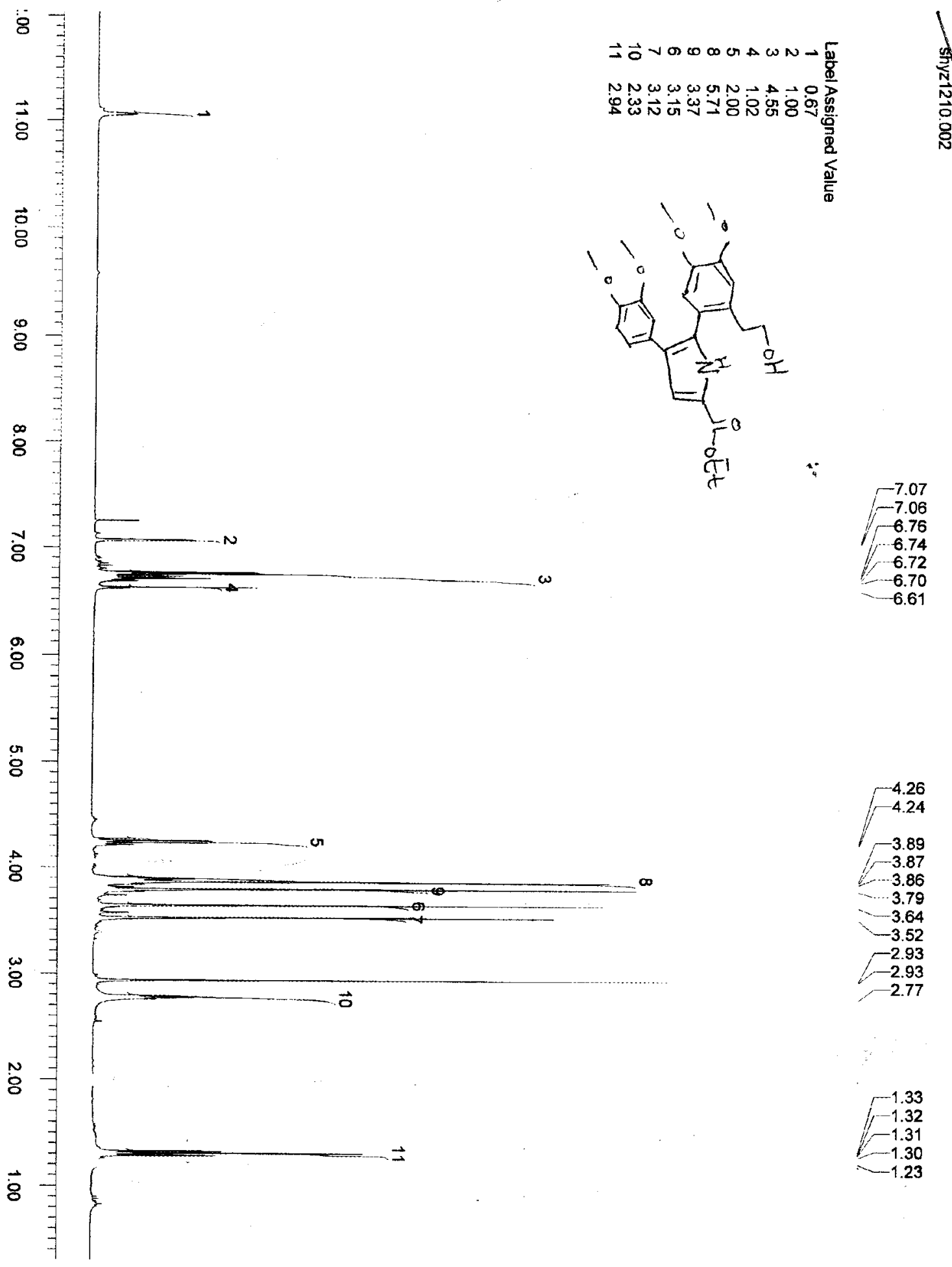




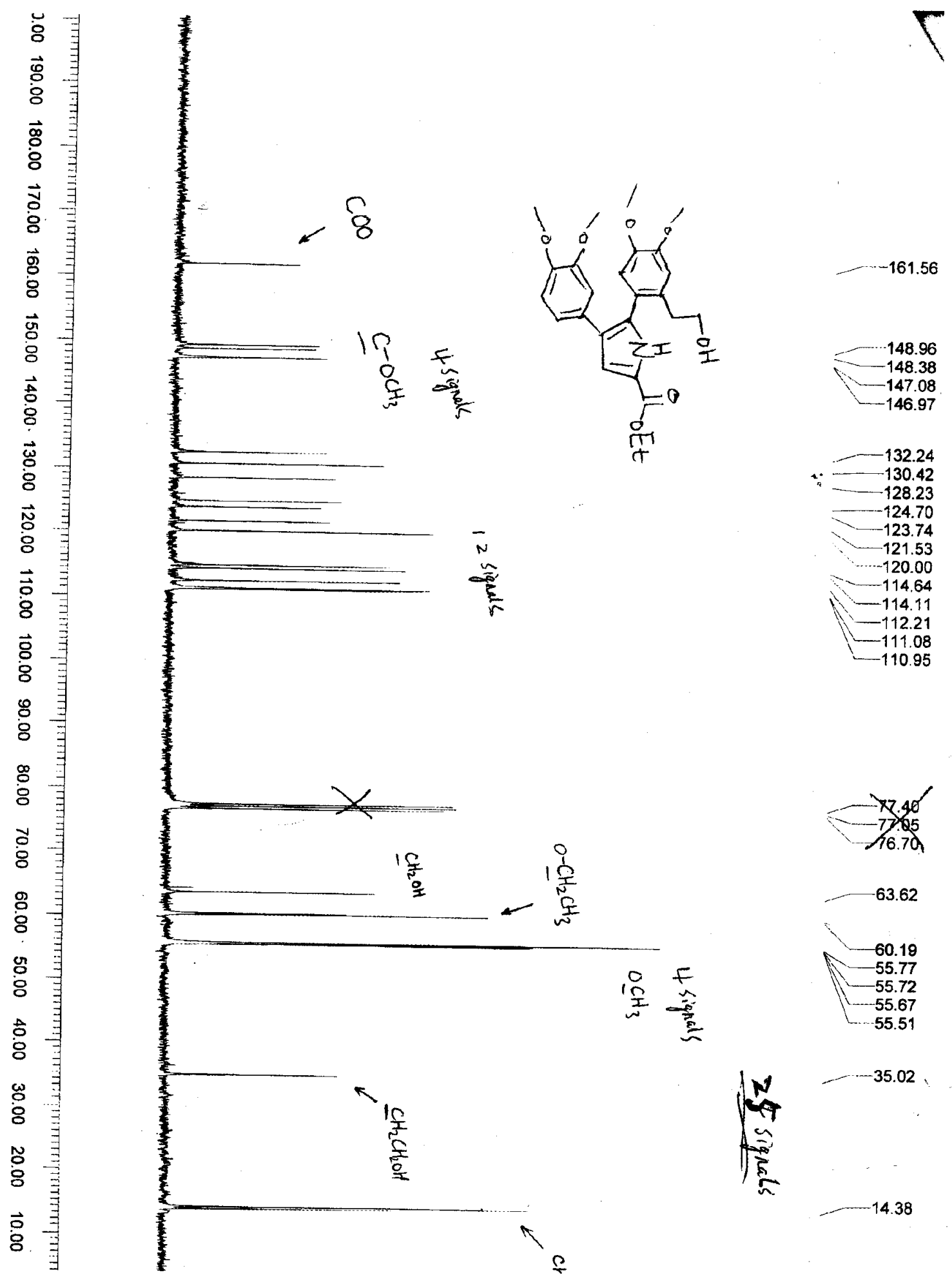


1-(3,4-dimethoxyphenyl)-8,9-dimethoxy-5,6-dihydropyrrolo[2,1-a]isoquinoline-3carboxylic acid ethyl ester (15).

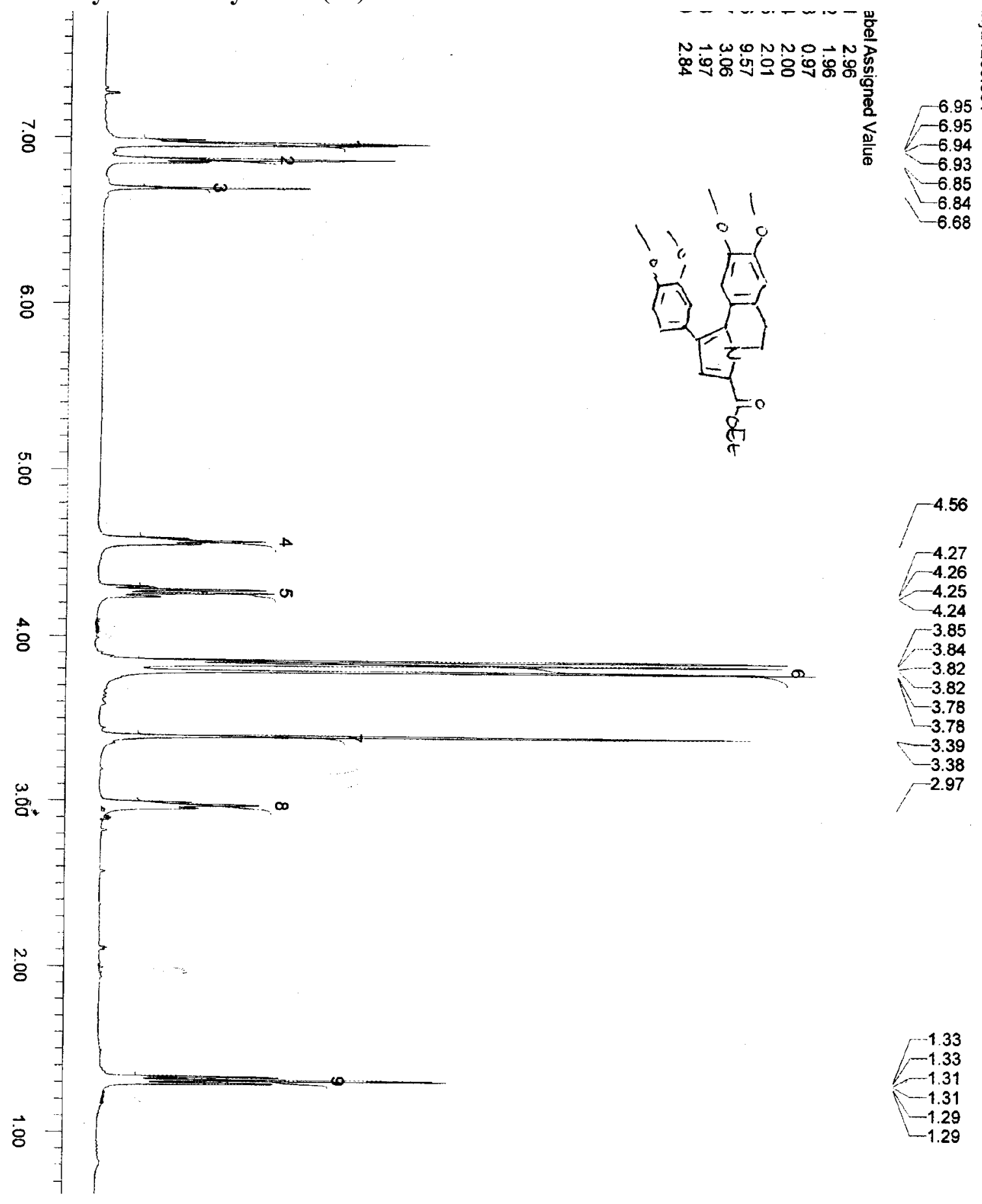




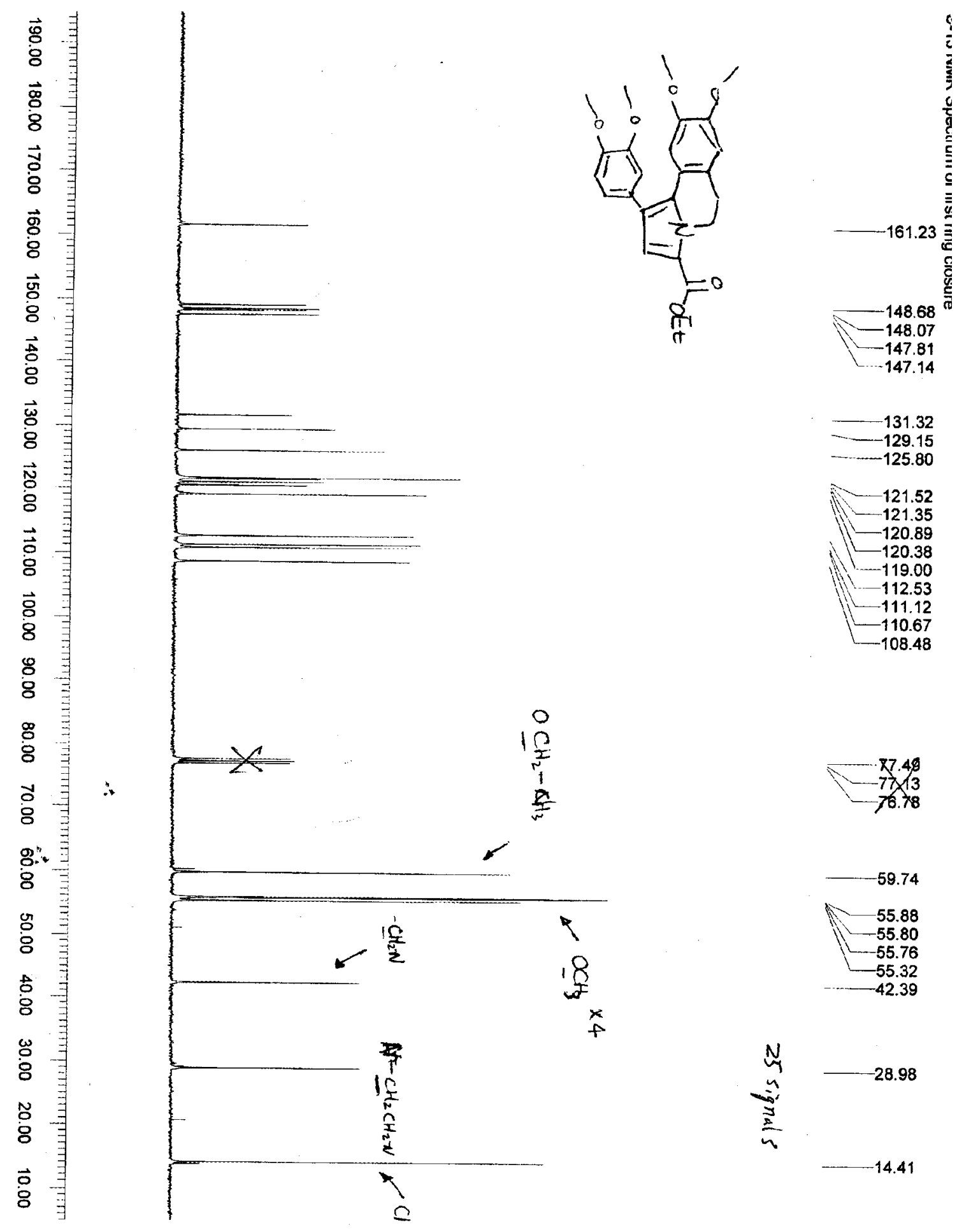


2-Bromo-1-(3,4-dimethoxyphenyl)-8,9-dimethoxy-5,6-dihydropyrrolo[2,1a]isoquinoline-3-carboxylic acid ethyl ester.

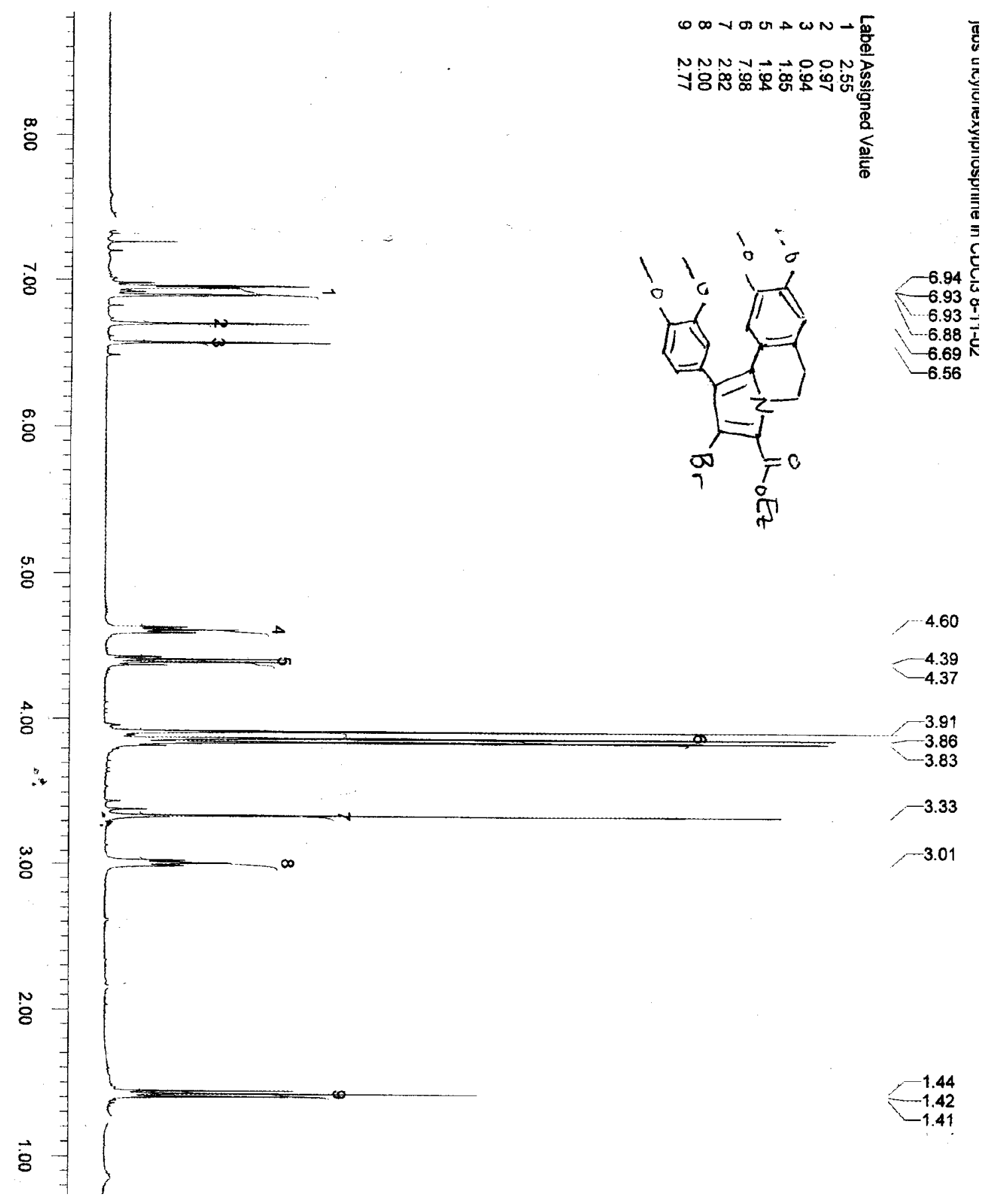




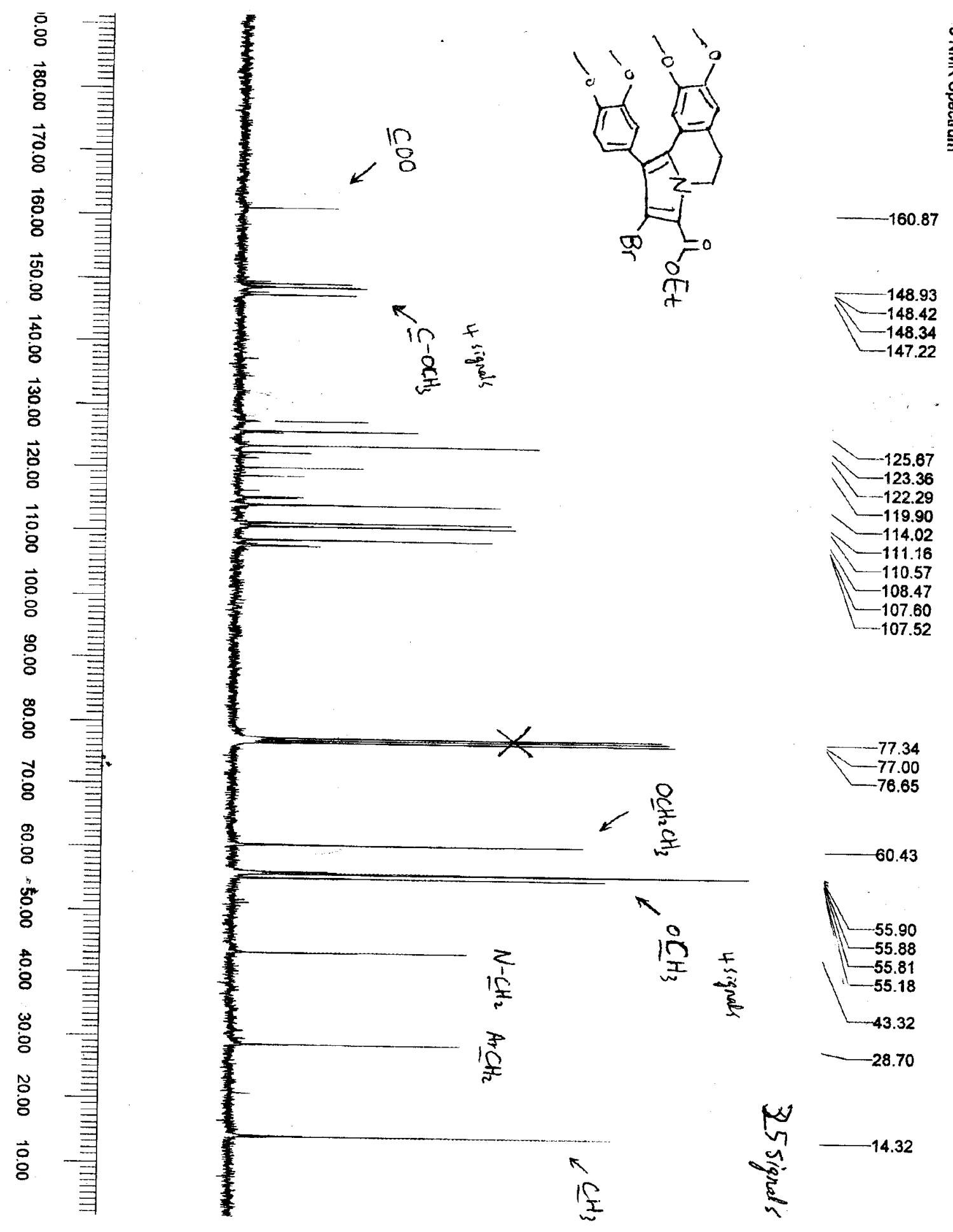


14-(3,4-dimethoxyphenyl)-2,3,11,12-tetramethoxy-8,9-dihydro-6Hchromeno[ $\left.4^{\prime}, 3^{\prime}: 4,5\right]$ pyrrolo[2,1-a]isoquinolin-6-one (Lamellarin $G$ trimethyl ether).

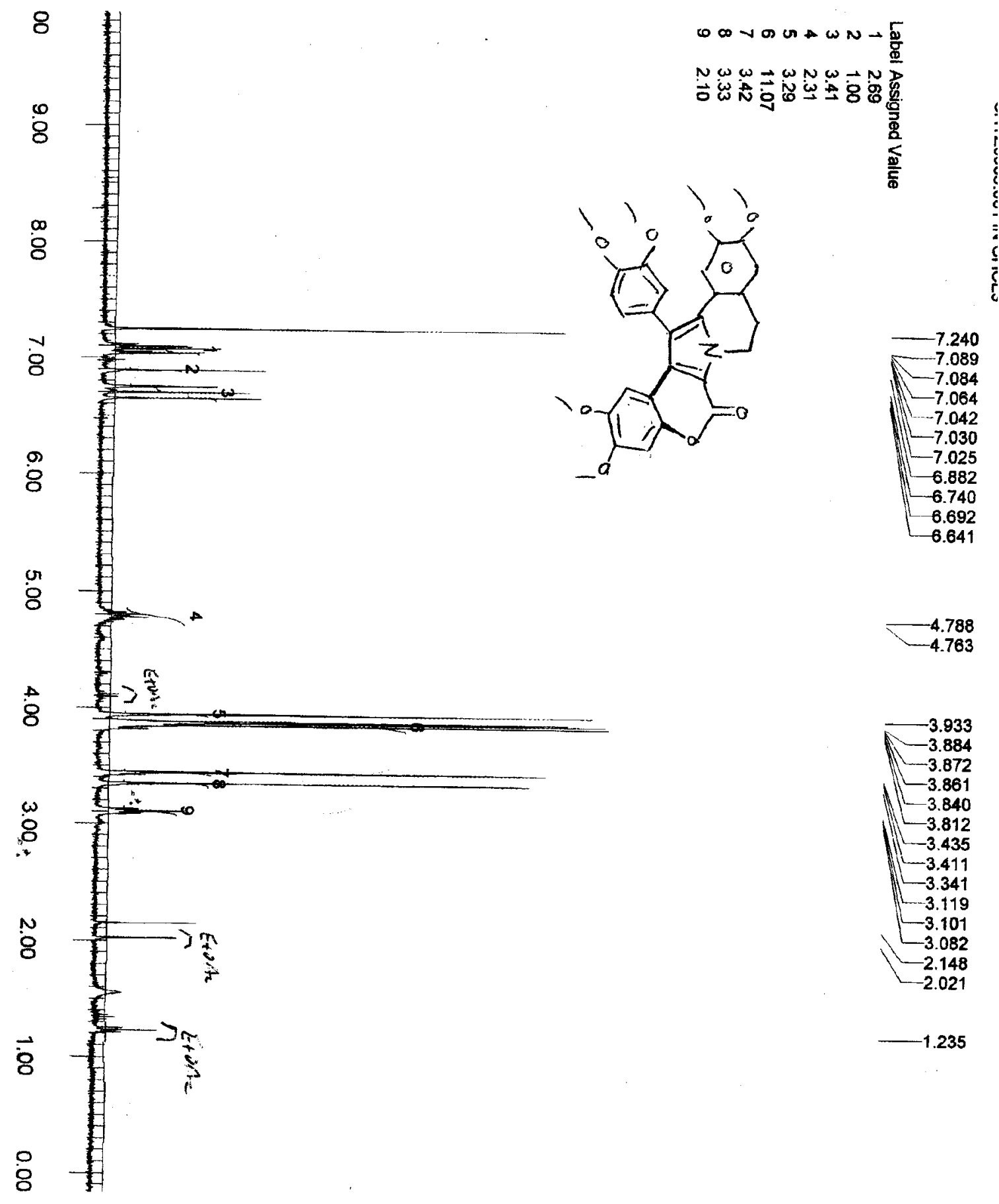




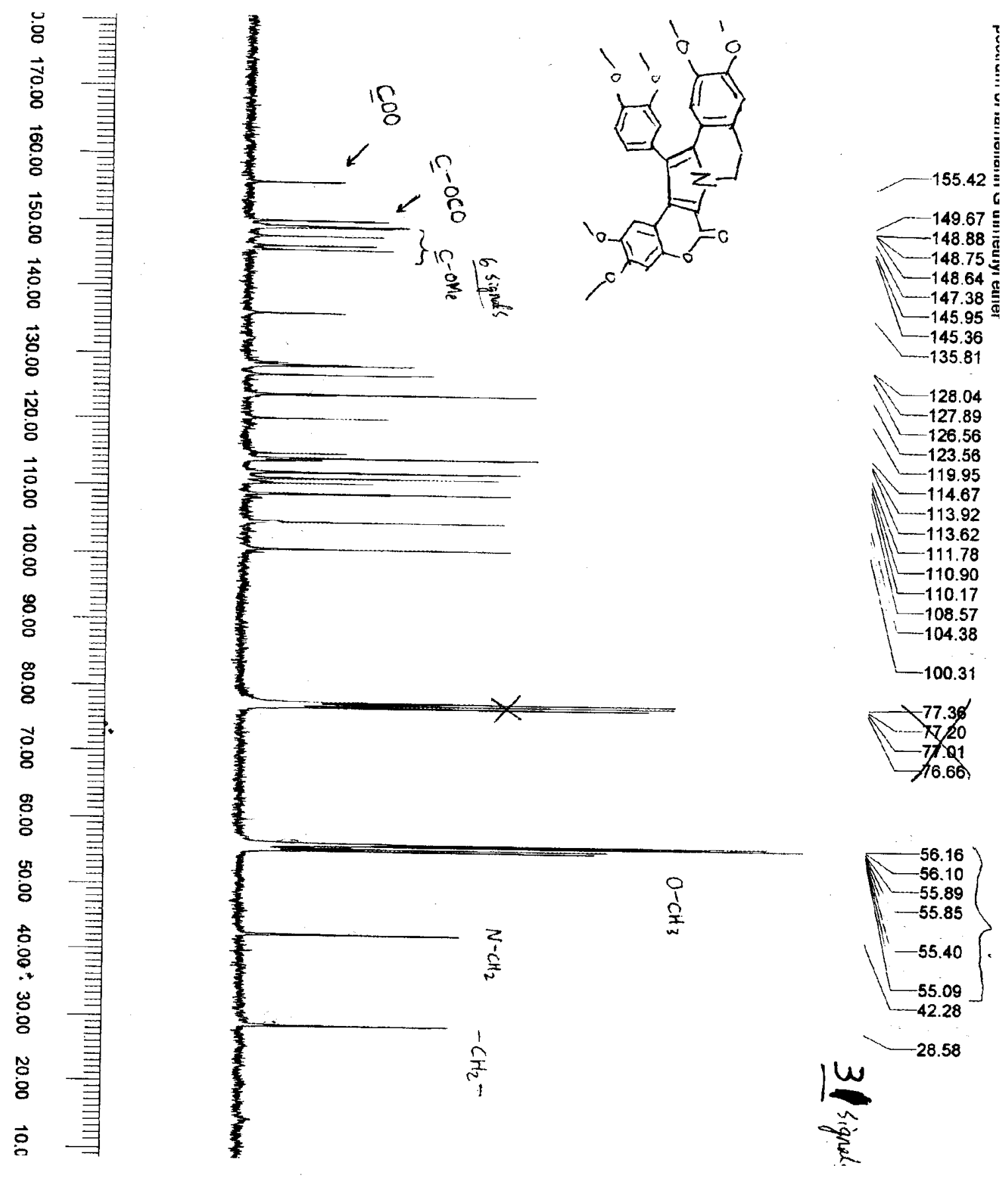

